\title{
Nutrition and Atopic Dermatitis
}

\author{
Naoko Kanda ${ }^{1}$, Toshihiko Hoashi ${ }^{2}$ and Hidehisa Saeki ${ }^{2}$ \\ ${ }^{1}$ Department of Dermatology, Nippon Medical School Chiba Hokusoh Hospital, Chiba, Japan \\ ${ }^{2}$ Department of Dermatology, Nippon Medical School, Tokyo, Japan
}

\begin{abstract}
Atopic dermatitis (AD) is a chronic eczematous disease characterized by $\mathrm{T}$ helper 2 (Th2)-shifted allergic immunity, skin barrier impairment, and pruritus. Oral intake of certain nutrients might help regulate AD. Serum 25-hydroxyvitamin D levels are often low in patients with AD, and oral vitamin D supplementation improves AD. Vitamin D increases regulatory $\mathrm{T}$ (Treg) cells, which promote tolerance to allergens and prevent allergic inflammation by inducing expression of filaggrin and cathelicidin in keratinocytes. Vitamin A strengthens Treg cells by inducing expression of forkhead box P3 and inhibits mediator release from mast cells and eosinophils. Serum levels of $\gamma$-linolenic acid and its metabolite, dihomo- $\gamma$-linolenic acid, are low in patients with $\mathrm{AD}$, and oral $\gamma$-linolenic acid improves AD through anti-inflammatory prostaglandin $\mathrm{D}_{1}$ and $\mathrm{E}_{1}$ derived from dihomo- $\gamma$-linolenic acid. Eicosapentaenoic acid and docosahexaenoic acid ameliorate $\mathrm{AD}$ by suppressing production of leukotriene $\mathrm{B}_{4}$, increasing ceramides in the stratum corneum, and through their metabolites, resolvin E1 and D1, which resolve inflammation. The probiotics Lactobacillus and Bifidobacteria improve the intestinal permeability barrier and induce Treg cells. Zinc levels in serum, hair, and erythrocytes are diminished in patients with AD. Zinc induces forkhead box P3 expression and increases Treg cells, and zinc-finger protein A20 suppresses nuclear factor-кB-dependent expression of inflammatory cytokines and cell-adhesion molecules. Oral supplementation of the above nutrients might have therapeutic or preventive roles in AD.
\end{abstract}

(J Nippon Med Sch 2021; 88: 171-177)

Key words: atopic dermatitis, probiotic, regulatory $\mathrm{T}$ cell, vitamin $\mathrm{D}$, zinc

\section{Introduction}

Atopic dermatitis (AD) is a chronic eczematous disease characterized by abnormal T helper 2 (Th2)-shifted allergic immunity, skin barrier impairment, and pruritus (Fig. $\mathbf{1}^{1-4}$. These elements are mutually related and are involved in the pathogenesis of AD. Patients with AD have diminished filaggrin ${ }^{3,4}$, water content, and ceramides in the stratum corneum ${ }^{3,4}$. Tight junctions in the granular layer are dysfunctional, with a decrease in zonula occludens- 1 and claudin- $1^{5}$. These impaired barriers allow penetration of allergens such as house dust mites, food, and pathogens, thus inducing sensitization by these allergens ${ }^{3,4}$. In early AD, allergens or scratches on keratinocytes induce secretion of thymic stromal lymphopoietin (TSLP), interleukin (IL)-33, and IL-25, thereby inducing innate lymphoid cell (ILC) 2 and basophils to secrete IL-4, IL-5, and IL-13. These type 2 cytokines induce dendritic cells (DCs) to migrate to draining lymph nodes and produce the chemokine CCL17, which attracts Th2 cells. Keratinocyte-derived TSLP induces Langerhans cells and DCs to promote differentiation of naïve $\mathrm{T}$ cells into Th2 cells via OX40-OX40L interaction. AD lesions are infiltrated by Th2 cells producing IL-4, IL-13, and IL31, and by IL-22-producing $\mathrm{T}$ cells, while chronic lesions are associated with Th1 cells producing interferon- $\gamma$ (IFN$\gamma)$. Furthermore, Th17 cells are infiltrated in AD lesions ${ }^{6}$. Patients with $\mathrm{AD}$ frequently have elevated serum $\operatorname{IgE}$ levels and $\operatorname{IgE}$ antibodies against allergens ${ }^{3,4}$. These patients develop pruritus owing to pruritogens such as histamine, TSLP, IL-31, IL-4, IL-13, and neuropeptides, and sensory nerves extend into the epidermis because of the increase in nerve growth factor and artemin and the de-

Correspondence to Naoko Kanda, MD, PhD, Department of Dermatology, Nippon Medical School Chiba Hokusoh Hospital,

1715 Kamagari, Inzai, Chiba 270-1694, Japan

E-mail: n-kanda@nms.ac.jp

https://doi.org/10.1272/jnms.JNMS.2021_88-317

Journal Website (https://www.nms.ac.jp/sh/jnms/) 


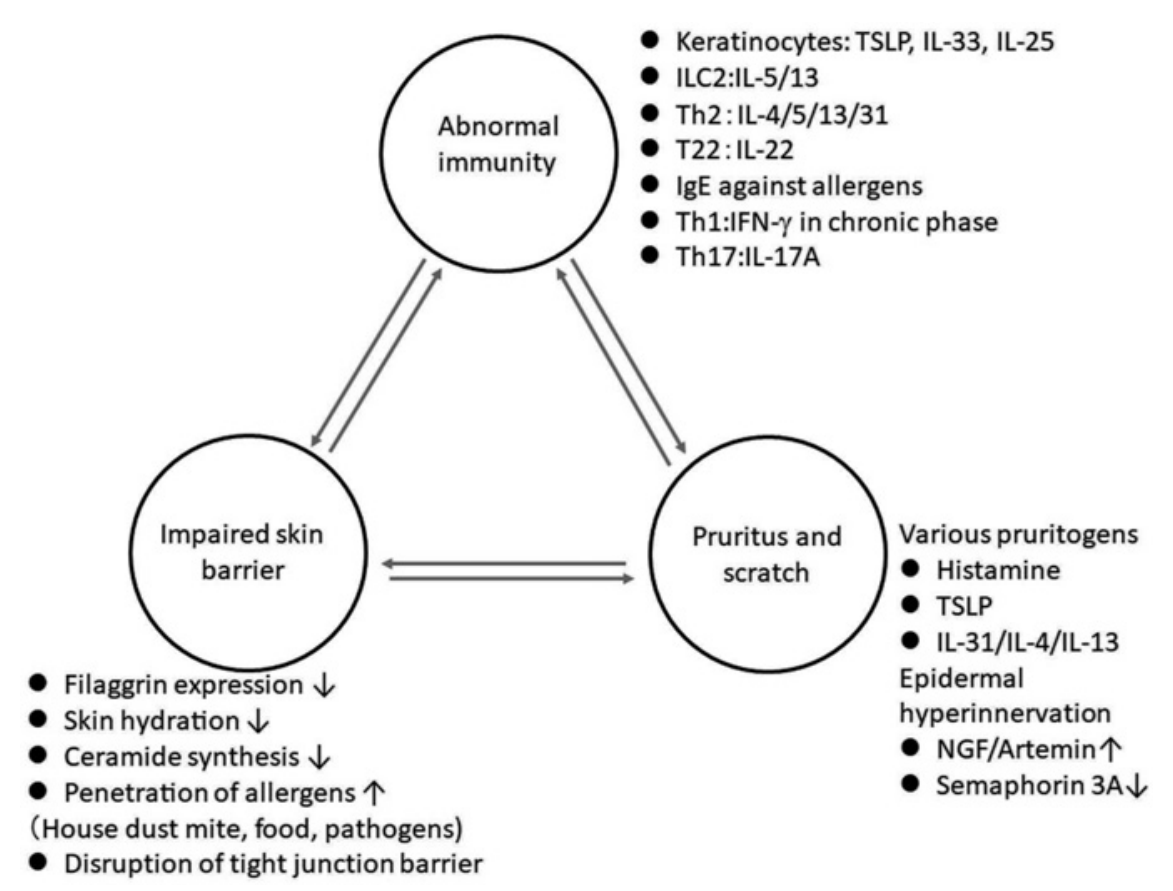

Fig. 1 The three elements involved in the pathogenesis of atopic dermatitis. Th2, T helper 2; IFN- $\gamma$, interferon- $\gamma$; IL-4, interleukin-4; ILC, innate lymphoid cells; NGF, nerve growth factor; TSLP, thymic stromal lymphopoietin.

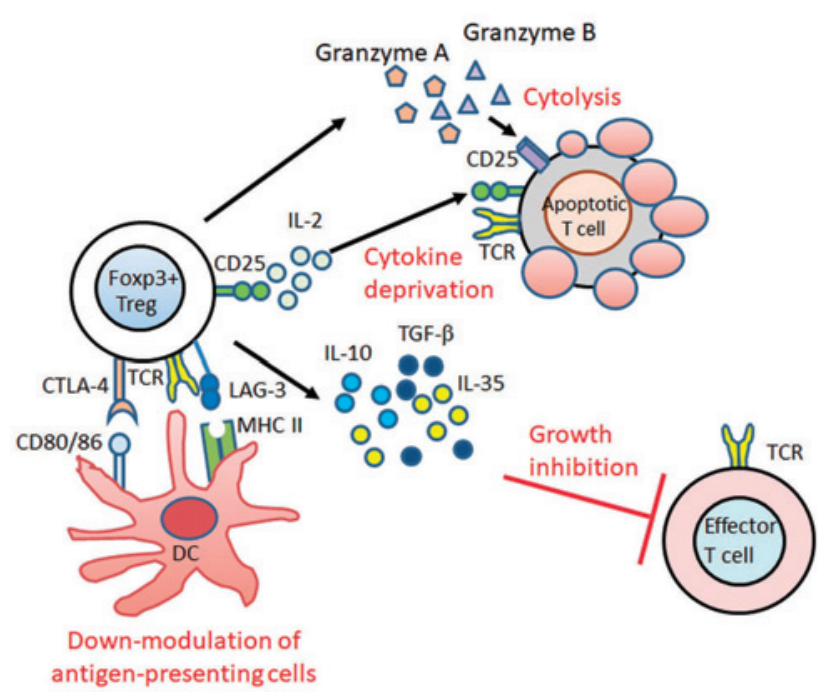

Fig. 2 Mechanisms underlying regulatory $\mathrm{T}$ (Treg) cellmediated suppression. Treg cells mediate tolerance to allergens through diverse mechanisms, namely, T-cell lysis by granzymes; interleukin (IL)2 deprivation by CD25; growth inhibition of effector T cells by inhibitory cytokines like IL-10, transforming growth factor- $\beta$ (TGF- $\beta$ ), and IL-35; and downregulation of antigen-presenting cells through lymphocyte-activation gene 3 (LAG-3)MHC class II and cytotoxic T-lymphocyte antigen 4 (CTLA-4)-CD80/86.

DC, dendritic cell; TCR, T cell receptor crease in semaphorin $3 \mathrm{~A}^{1,3}$.

$\mathrm{CD} 4{ }^{+} \mathrm{CD} 25^{+}$forkhead box protein 3 (FOXP3) $^{+}$regulatory $\mathrm{T}$ (Treg) cells sustain immune tolerance to allergens and prevent allergic inflammation. The induction of Treg cells is necessary for control of $\mathrm{AD}^{7}$. Treg cells are classified as natural Treg (nTreg) and induced Treg (iTreg) cells. nTreg cells arise in the thymus and stably express FOXP3 with T cell receptor (TCR) repertoires toward selfantigens. iTreg cells arise extrathymically from conventional $\mathrm{T}$ cells in the presence of transforming growth factor- $\beta$ (TGF- $\beta$ ), retinoic acid (RA), and TCR-mediated antigen presentation, from either $\mathrm{CD}_{103^{+}} \mathrm{DCs}$ in the intestines or $\mathrm{F} 4 / 80^{+} \mathrm{CD}_{11 \mathrm{c}^{+}}$macrophages in airways. In iTreg cells, FOXP3 expression is less stable with TCR repertoires toward allergens ${ }^{7}$. Treg cell suppressive functions are mediated by multiple mechanisms (Fig. 2), including T-cell cytolysis through granzymes; internalization and degradation of IL-2 after binding to CD25 on the target T cell (IL-2 deprivation); release of IL-10, TGF- $\beta$, and IL-35, which suppress proliferation of effector $\mathrm{T}$ cells; and downregulation of antigen-presenting cells through interaction of lymphocyte-activation gene 3-MHC class II and cytotoxic T-lymphocyte antigen 4-CD80/86. Treg cells suppress ILC2 expansion, mediator release from mast cells, conversion of conventional $\mathrm{T}$ cells into Th2 cells, and IgE production by B cells ${ }^{7}$.

The pathogenesis of AD involves genetic and environ- 


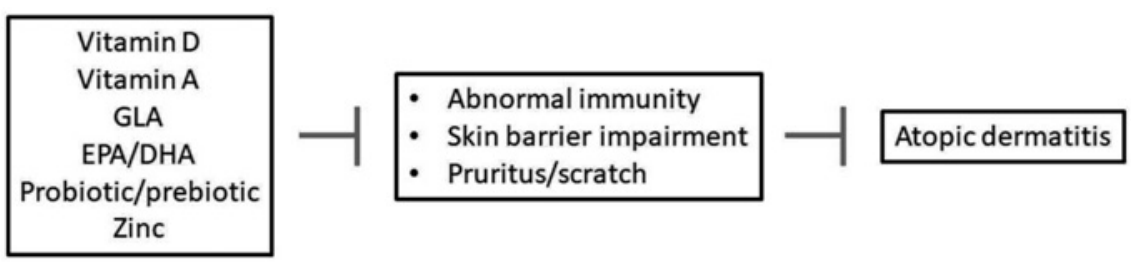

Fig. 3 Dietary nutrients may improve atopic dermatitis by suppressing abnormal immunity, skin barrier impairment, and pruritus.

GLA, $\gamma$-linolenic acid; EPA, eicosapentaenoic acid; DHA, docosahexaenoic acid

mental factors, including $\operatorname{diet}^{8}$. AD might be regulated by oral intake of certain nutrients, including vitamin $\mathrm{D}$, vitamin A, $\gamma$-linolenic acid (GLA), eicosapentaenoic acid (EPA), probiotics, and zinc, via suppression of abnormal immunity, skin barrier impairment, and pruritus (Fig. $3)^{8-10}$. This article reviews recent studies of the regulatory effects of individual nutrients on $\mathrm{AD}$ and the possible therapeutic and preventive roles of oral supplementation of these nutrients in AD.

\section{Vitamin D}

Vitamin D binds vitamin D receptor (VDR), and ligandbound VDR interacts with the retinoid $X$ receptor ( $R X R$ ). The complex vitamin D/VDR-RXR binds vitamin D response elements on various genes, thereby activating or repressing their expression ${ }^{11}$. There are two ways to obtain vitamin D: dietary intake and ultraviolet-induced synthesis in the skin ${ }^{12}$. Cod liver oil, salmon, tuna, beef liver, and eggs are rich in vitamin D.

During pregnancy, a vitamin D-deficient diet induced hypermethylation of the IFN- $\gamma$ gene, reduced IFN- $\gamma$ expression, and enhanced IL-4 expression in offspring rats ${ }^{13}$. 1,25-Hydroxyvitamin D3 inhibits DC maturation and induces tolerogenic DCs with lower antigen presentation but higher IL-10 production. 1,25-Hydroxyvitamin D3 enhances FOXP3 gene expression by binding to the nuclear VDR that recognizes the target response element DNA sequence recently identified in the intronic region of the human FOXP3 gene $^{14}$. Additionally, 1,25-hydroxyvitamin D3 inhibits expressions of IFN- $\gamma$, tumor necrosis factor- $\alpha$ (TNF- $\alpha$ ), IL-9, IL-17A, and IL-22 in T cells and inhibits Th2 differentiation ${ }^{15}$. In BALB/c mice, dietary vitamin D3 suppressed dinitrofluorobenzene-induced ear swelling, thereby increasing the number and suppressive activity of Treg cells in draining lymph nodes ${ }^{16}$.

1,25-Hydroxyvitamin D3 promotes apoptosis of B cells and inhibits ILC2 activation ${ }^{15}$. 1,25-Hydroxyvitamin D3 inhibits peroxidase release from eosinophils ${ }^{17}$ and pro- motes eosinophil surface expression of CXCR4, leading to eosinophil recruitment to non-inflammatory sites where CXCL12, the ligand of CXCR4, is constitutively expressed $^{18}$.

$\mathrm{AD}$ lesions are associated with a decrease in cathelicidin levels, leading to microbial superinfections such as Staphylococcus aureus and allergic sensitization. 1,25Hydroxyvitamin D3 induces cathelicidin expression in keratinocytes $^{19}$. In mice, the intraperitoneal VDR agonist ZK203278 improved ovalbumin-triggered AD-like eczema and increased expressions of filaggrin, loricrin, involucrin, transglutaminase 1 , and $\beta$-defensin- 2 and -3 in lesional skin ${ }^{20}$.

In patients with $\mathrm{AD}$, serum 25-hydroxyvitamin $\mathrm{D}$ levels were lower than in controls (standardized mean difference $=-2.03 \mathrm{ng} / \mathrm{mL}$ ). Scoring of $\mathrm{AD}$ (SCORAD) and the eczema area and severity index decreased (standardized mean difference $=-5.85$ ) after daily vitamin $\mathrm{D}$ supplementation with 1,000 to $2,000 \mathrm{IU}$ cholecalciferol for 1 to 2 months $^{21-25}$. Future large-scale clinical trials should assess the effects of supplementation on AD outcomes over a longer period.

\section{Vitamin A}

Liver, fish, eggs, and butter are rich in vitamin A (retinol $)^{26}$. Most vitamin A activity depends on its active metabolites, RAs, which are formed by retinal dehydrogenases in epithelial and immune cells ${ }^{26,27}$. RAs act via retinoic acid receptors and RXRs.

RA is produced by DCs and induces naïve $\mathrm{T}$ cells to differentiate into Treg cells ${ }^{15}$ by promoting histone acetylation of FOXP3 promoter in cooperation with TGF- $\beta^{28}$. RA induces tolerogenic DCs expressing IL-10, TGF- $\beta$, and IL-27 and promotes production of IgA-producing B cells. Furthermore, RA suppresses IgE production by anti-CD 40 plus IL-4-stimulated human peripheral blood mononuclear cells ${ }^{29}$, and it antagonizes ILC2 function and mediator release from mast cells and eosinophils ${ }^{29}$. 

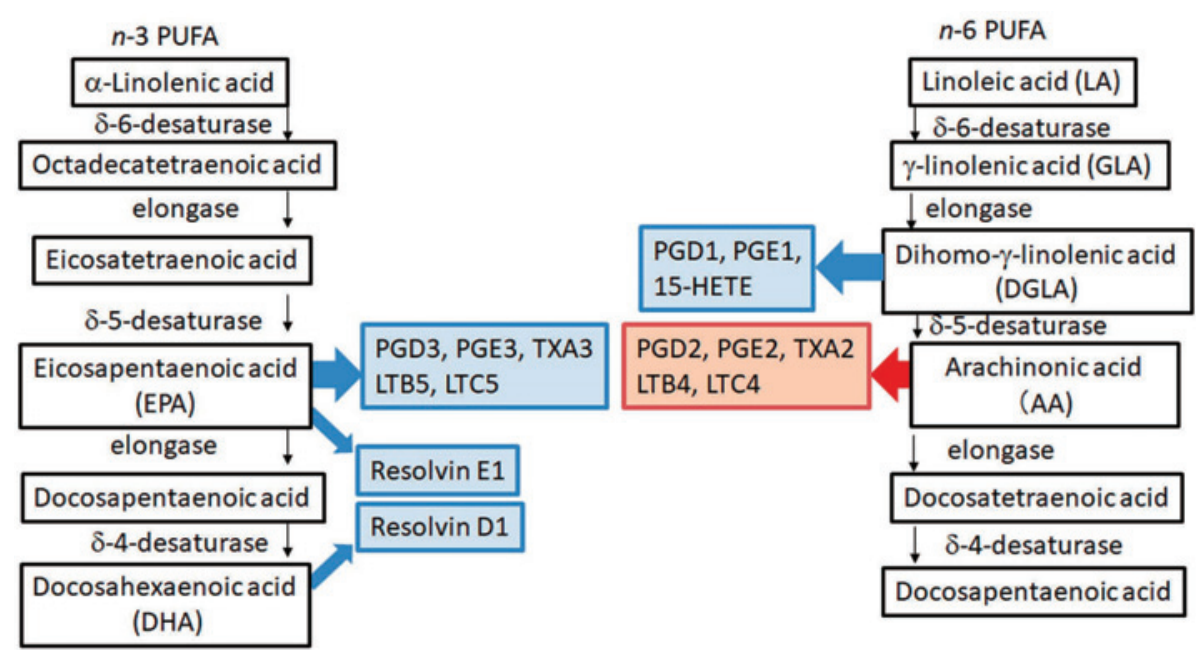

Fig. 4 Biosynthetic pathways of n-3 and n-6 polyunsaturated fatty acids (PUFAs) and their metabolized eicosanoids and resolvins. Eicosanoids and resolvins in the red box are pro-inflammatory; those in the blue box are anti-inflammatory. LT, leukotriene; PG, prostaglandin; TX, thromboxane; 15-HETE, 15-hydroxy-5,8,11,13eicosatetraenoic acid.

As compared with mice fed a vitamin A-sufficient diet, mice fed a vitamin A-deficient diet had more severe eczema induced by ovalbumin and greater mast cell accumulation, higher IL-4 and IL-13 mRNAs, higher serum IgG1 and IgE levels, and lower IgG2a serum levels and lower IFN- $\gamma$ mRNA expression in skin, which reflect lower Th1 immune response ${ }^{30}$.

In children with $\mathrm{AD}$, serum vitamin $\mathrm{A}$ levels are low and negatively correlated with SCORAD ${ }^{31}$. Oral alitretinoin (9-cis RA) reduced SCORAD in adult patients with $\mathrm{AD}^{32,33}$. Large randomized controlled trials are required in order to confirm the effects of oral vitamin A.

\section{n-6 Polyunsaturated Fatty Acids (PUFAs)}

The simplest members of the $n-6$ and $n-3$ PUFAs, linoleic acid (LA) and $\alpha$-linolenic acid, respectively, make up greater than $95 \%$ of dietary PUFAs and cannot be synthesized by mammals (Fig. 4) ${ }^{34}$. Vegetable oils and margarine are rich in LA.

LA is converted to GLA by $\delta-6$ desaturase, to dihomo$\gamma$-linolenic acid (DGLA) by elongase, and to arachidonic acid (AA) by $\delta$-5-desaturase ${ }^{34}$. AA is incorporated into the membranes of immune cells such as mast cells and macrophages. When tissues are exposed to injury or cytokines, AA is released from membranes and converted into four-series leukotrienes (LTs) like $\mathrm{LTB}_{4}$, thus promoting IgE production by $\mathrm{B}$ cells or two-series prostaglandins (PGs) like $\mathrm{PGD}_{2}$, activating IL-4, IL-5, and IL-13 production by Th2 cells, and exacerbating Th2 responses in $\mathrm{AD}^{34}$.
Patients with AD have low serum GLA and DGLA levels, possibly because of impaired $\delta-6$ desaturase activity. These levels are negatively correlated with transepidermal water loss and SCORAD ${ }^{35}$. Oral intake of $\mathrm{GLA}^{36}$, GLA-rich borage oil ${ }^{37}$, and evening primrose oil ${ }^{38,39}$ improved AD. Moreover, oral intake of black currant seed oil containing GLA plus $\alpha$-linolenic acid reduced $\mathrm{AD}$ prevalence in 12-month-old infants ${ }^{40}$. Dietary GLA is converted into DGLA by elongase but does not increase $\mathrm{AA}$ in the epidermis, since $\delta$-5-desaturase, which converts DGLA into AA, is absent in the epidermis ${ }^{35}$.

Dietary GLA may improve AD, at least partly, by conversion to DGLA. The DGLA-derived eicosanoids $\mathrm{PGE}_{1}$ and 15-hydroxy-eicosatrienoic acid are anti-inflammatory, and $\mathrm{PGE}_{1}$ inhibits histamine release from mast cells ${ }^{35}$. 15Hydroxy-eicosatrienoic acid inhibits $\mathrm{LTB}_{4}$ generation from basophils ${ }^{35}$. DGLA induces mast cells to release $\mathrm{PGD}_{1}$, which suppresses mast cell degranulation and TSLP production in keratinocytes ${ }^{41}$.

\section{n-3 PUFAs}

Fish are rich in n-3 PUFAs, EPA, and docosahexaenoic acid (DHA). EPA and DHA compete with AA for incorporation into membranes of inflammatory cells ${ }^{34}$. EPA acts as a substrate for cyclooxygenases and lipoxygenases, which convert AA into eicosanoids, thus reducing AA-derived inflammatory eicosanoids. Topical EPA/ DHA ameliorated Dermatophagoides farinae extractinduced AD-like dermatitis by blocking $\mathrm{LTB}_{4}$ production $^{42}$. In mice, oral EPA ethyl ester ameliorated AD-like 
eczema and increased ceramides in the stratum corneum $^{43}$. EPA-derived eicosanoids, five-series LTs, and three-series PGs are anti-inflammatory. $\mathrm{LTB}_{5}$ counteracts $\mathrm{LTB}_{4}$-induced proliferation of keratinocytes and neutrophil chemokinesis ${ }^{44}$. Moreover, EPA and DHA are metabolized into resolvin $E_{1}$ and $D_{1}$, respectively, which resolve inflammation. In NC/Nga mice, intraperitoneal resolvin $\mathrm{E}_{1}$ ameliorated 2,4-dinitrofluorobenzene-induced AD-like eczema by suppressing infiltration of eosinophils, mast cells, and CD4+ and CD8+ T cells in skin lesions and reducing serum IgE levels ${ }^{45}$.

In pregnant women, intake of oral EPA plus DHA from the 25th gestational week through 3.5 months of breastfeeding reduced the prevalence of IgE-associated eczema in infants ${ }^{46}$. In adults with $\mathrm{AD}$, oral intake of fish oil containing EPA plus DHA for 12 weeks improved $\mathrm{AD}^{46}$. Larger and longer randomized controlled trials should be conducted to assess the effects of oral EPA/DHA.

\section{Probiotics and Prebiotics}

Probiotics are living microorganisms that are beneficial to the host, e.g., lactic acid-producing Lactobacillus and Bifidobacteria ${ }^{47}$. Prebiotics are non-digestible fructooligosaccharides, inulins, and galactooligosaccharides that stimulate growth of beneficial bacteria.

In patients with $\mathrm{AD}$, intestinal permeability is increased, inducing transfer of exogenous antigens ${ }^{48,49}$. Probiotics modulate the intestinal microbiome, improve the intestinal barrier, and modulate the intestine-skin immune axis ${ }^{48,49}$. The number of Treg cells in CD4+ T cells is lower in patients with AD. Probiotics increase Treg cells and their secretion of IL-10 and TGF- $\beta$ in mesenteric lymph nodes ${ }^{49-51}$. Treg cells migrate to inflammatory skin lesions and suppress IL-4, IL-5, IL-13, and IL-17Amediated allergic responses and reduce TSLP expression in the epidermis ${ }^{51}$. Prebiotics enhance production of butyrate, which expands and stabilizes iTreg cells through histone acetylation of FOXP3 protein by inhibiting histone deacetylase ${ }^{49,52}$. Moreover, prebiotics increase intestinal $\operatorname{Ig}$ A secretion ${ }^{49}$.

Studies of probiotic supplementation reported positive and negative effects on the prevention and improvement of AD. A meta-analysis of random controlled trials (RCTs) showed that probiotics had a protective role in the development of $\mathrm{AD}$ when administered during the pre- and post-natal period (odds ratio [OR] 0.61, p $<0.001$ ) but not when administered during the post-natal period only (OR 0.95, $\mathrm{p}=0.82)^{53}$. However, an updated meta-analysis reported that probiotics did not produce siguificant preventive effects when administered solely to infants (OR $0.88, \mathrm{p}=0.56$ ) while produced preventive effects when administered both to pregnant mothers and their infants (OR 0.71, $\mathrm{p}=0.0006)$ and solely to pregnant mothers (OR 0.54, $\mathrm{p}=0.001)^{54}$. The clinical outcomes of probiotics might be influenced by timing of administration, duration, strains, or dosage. More robust RCTs using standardized measurements, and studies of the mechanisms underlying the effects of probiotic supplementation on AD during pregnancy and the postpartum period, are necessary in order to evaluate the long-term effects of probiotics.

\section{Zinc}

Oysters, pork liver, and beef shoulder are rich in zinc, an essential trace element affecting the activity of more than 300 enzymes. Zinc induces the zinc-finger protein A20, which suppresses expression of nuclear factor- $\kappa \mathrm{B}-$ dependent genes, such as adhesion molecules (intercellular adhesion molecule-1) and inflammatory cytokines (IL$1 \beta, \mathrm{TNF}-\alpha)^{55}$. Zinc aspartate suppresses proliferation, and IFN- $\gamma$, IL-5, and IL-17A production in anti-CD3/CD28activated human $\mathrm{T}$ cells ${ }^{56}$. In an allogeneic mixed lymphocyte culture, zinc sulfate increased and stabilized alloantigen-specific iTreg cells by increasing FOXP3 and Kruppel-like factor 10 mRNAs, while decreasing IFN regulatory factor $1 \mathrm{mRNA}{ }^{57}$.

In patients with $\mathrm{AD}$, zinc levels are low in serum, hair, and erythrocytes ${ }^{58}$, and erythrocyte zinc levels are negatively correlated with SCORAD ${ }^{9,59}$. In children with $\mathrm{AD}$, oral zinc oxide decreased trans-epidermal water loss, the eczema area and severity index, and pruritus ${ }^{60}$. Zinc should be supplemented with copper at a ratio of about 10:1, because zinc may interfere with intestinal copper absorption 9 .

\section{Conclusion}

We reviewed studies of the effects of nutrients on $A D$ and possible therapeutic and preventive roles of their oral supplementation in AD. Vitamin D, vitamin A, GLA, EPA/DHA, probiotics/prebiotics, and zinc might help regulate $\mathrm{AD}$ by inducing Treg cells or restoring the impaired skin barrier. Oral supplementation with these nutrients might improve or prevent AD. Future studies should explore the precise mechanisms underlying the improvement or prevention of $\mathrm{AD}$ by nutritional supplementation and should examine longitudinal effects, to obtain sufficient evidence regarding the effectiveness of these nutrients. 
Conflict of Interest: The authors declare no conflicts of interest.

\section{References}

1. Kanda N, Hoashi T, Saeki H. The roles of sex hormones in the course of atopic dermatitis. Int J Mol Sci. 2019 Sep 20;20(19):4660.

2. Saeki H. Management of atopic dermatitis in Japan. J Nippon Med Sch. 2017;84(1):2-11.

3. Furue M, Chiba T, Tsuji G, et al. Atopic dermatitis: immune deviation, barrier dysfunction, IgE autoreactivity and new therapies. Allergol Int. 2017 Jul;66(3):398-403.

4. Egawa G, Kabashima K. Barrier dysfunction in the skin allergy. Allergol Int. 2018 Jan;67(1):3-11.

5. Yuki T, Tobiishi M, Kusaka-Kikushima A, Ota Y, Tokura $Y$. Impaired tight junctions in atopic dermatitis skin and in a skin-equivalent model treated with interleukin-17. PLoS One. 2016;11(9):e0161759.

6. Nomura T, Honda T, Kabashima K. Multipolarity of cytokine axes in the pathogenesis of atopic dermatitis in terms of age, race, species, disease stage and biomarkers. Int Immunol. 2018 Aug 30;30(9):419-28.

7. Noval Rivas M, Chatila TA. Regulatory T cells in allergic diseases. J Allergy Clin Immunol. 2016 Sep;138(3):639-52.

8. Ito M, Morita T, Okazaki S, et al. Dietary habits in adult Japanese patients with atopic dermatitis. J Dermatol. 2019 Jun;46(6):515-21.

9. Vaughn AR, Foolad N, Maarouf M, Tran KA, Shi VY. Micronutrients in atopic dermatitis: a systematic review. J Altern Complement Med. 2019 Jun;25(6):567-77.

10. Finch J, Munhutu MN, Whitaker-Worth DL. Atopic dermatitis and nutrition. Clin Dermatol. 2010 Nov-Dec;28(6): 605-14.

11. Bivona G, Agnello L, Ciaccio M. Vitamin D and immunomodulation: Is it time to change the reference values? Ann Clin Lab Sci. 2017 Aug;47(4):508-10.

12. Kanda N, Hoashi T, Saeki H. Nutrition and psoriasis. Int J Mol Sci. 2020 Jul 29;21(15):5405.

13. Jiao X, Wang L, Wei Z, Liu B, Liu X, Yu X. Vitamin D deficiency during pregnancy affects the function of Th1/Th2 cells and methylation of IFN- $\gamma$ gene in offspring rats. Immunol Lett. 2019 Aug;212:98-105.

14. Kang SW, Kim SH, Lee N, et al. 1,25-Dihyroxyvitamin D3 promotes FOXP3 expression via binding to vitamin D response elements in its conserved noncoding sequence region. J Immunol. 2012 Jun 1;188(11):5276-82.

15. Hufnagl K, Jensen-Jarolim E. Vitamin A and D in allergy: from experimental animal models and cellular studies to human disease. Allergo J Int. 2018;27(3):72-8.

16. Gorman S, Geldenhuys S, Judge M, Weeden CE, Waithman J, Hart PH. Dietary vitamin D increases percentages and function of regulatory $\mathrm{T}$ cells in the skin-draining lymph nodes and suppresses dermal inflammation. J Immunol Res. 2016;2016:1426503.

17. Ethier C, Yu Y, Cameron L, Lacy P, Davoine F. Calcitriol reduces eosinophil necrosis which leads to the diminished release of cytotoxic granules. Int Arch Allergy Immunol. 2016;171(2):119-29.

18. Hiraguchi $\mathrm{Y}$, Tanida $\mathrm{H}$, Sugimoto $\mathrm{M}$, et al. 1,25Dihydroxyvitamin D3 upregulates functional C-x-C chemokine receptor type 4 expression in human eosinophils. Int Arch Allergy Immunol. 2012;158 Suppl 1:51-7.

19. Bikle DD. Vitamin D and the immune system: role in protection against bacterial infection. Curr Opin Nephrol Hy- pertens. $2008 \mathrm{Jul} ; 17(4): 348-52$.

20. Hartmann B, Riedel R, Jörss K, et al. Vitamin D receptor activation improves allergen-triggered eczema in mice. $\mathrm{J}$ Invest Dermatol. 2012 Feb;132(2):330-6.

21. Umar M, Sastry KS, Al Ali F, Al-Khulaifi M, Wang E, Chouchane AI. Vitamin D and the pathophysiology of inflammatory skin diseases. Skin Pharmacol Physiol. 2018; 31(2):74-86.

22. Filoni A, Vestita M, Congedo M, Giudice G, Tafuri S, Bonamonte D. Association between psoriasis and vitamin D: Duration of disease correlates with decreased vitamin D serum levels: An observational case-control study. Medicine (Baltimore). 2018 Jun;97(25):e11185.

23. Kanda N, Hau CS, Tada Y, Sato S, Watanabe S. Decreased serum LL-37 and vitamin D3 levels in atopic dermatitis: relationship between IL-31 and oncostatin M. Allergy. 2012 Jun;67(6):804-12.

24. Hattangdi-Haridas SR, Lanham-New SA, Wong WHS, Ho MHK, Darling AL. Vitamin D deficiency and effects of vitamin D supplementation on disease severity in patients with atopic dermatitis: a systematic review and metaanalysis in adults and children. Nutrients. 2019 Aug 9;11 (8):1854.

25. Kim MJ, Kim SN, Lee YW, Choe YB, Ahn KJ. Vitamin D Status and efficacy of vitamin D supplementation in atopic dermatitis: a systematic review and meta-analysis. Nutrients. 2016 Dec 3;8(12):789.

26. Reichrath J, Lehmann B, Carlberg C, Varani J, Zouboulis CC. Vitamins as hormones. Horm Metab Res. 2007 Feb;39 (2):71-84.

27. Khalil S, Bardawil T, Stephan C, et al. Retinoids: a journey from the molecular structures and mechanisms of action to clinical uses in dermatology and adverse effects. J Dermatolog Treat. 2017 Dec;28(8):684-96.

28. Kang SG, Lim HW, Andrisani OM, Broxmeyer HE, Kim $\mathrm{CH}$. Vitamin A metabolites induce gut-homing FoxP3+ regulatory T cells. J Immunol. 2007 Sep 15;179(6):3724-33.

29. Worm M, Herz U, Krah JM, Renz H, Henz BM. Effects of retinoids on in vitro and in vivo IgE production. Int Arch Allergy Immunol. 2001 Jan-Mar;124(1-3):233-6.

30. Yang H, Chen JS, Zou WJ, et al. Vitamin A deficiency exacerbates extrinsic atopic dermatitis development by potentiating type 2 helper $\mathrm{T}$ cell-type inflammation and mast cell activation. Clin Exp Allergy. 2020 Aug;50(8):94253.

31. Xiang J, Wang H, Li T. Comorbidity of vitamin A and vitamin D deficiency exacerbates the severity of atopic dermatitis in children. Dermatology. 2019;235(3):196-204.

32. Grahovac M, Molin S, Prinz JC, Ruzicka T, Wollenberg A. Treatment of atopic eczema with oral alitretinoin. Br J Dermatol. 2010 Jan;162(1):217-8.

33. Son JH, Park SY, Cho YS, et al. Two cases of successful treatment of refractory chronic inflammatory skin disease, atopic dermatitis and psoriasis with oral alitretinoin. Ann Dermatol. 2017 Aug;29(4):503-6.

34. Calder PC, Kremmyda LS, Vlachava M, Noakes PS, Miles EA. Is there a role for fatty acids in early life programming of the immune system? Proc Nutr Soc. 2010 Aug;69 (3):373-80.

35. Yen $\mathrm{CH}$, Dai YS, Yang YH, Wang LC, Lee JH, Chiang BL. Linoleic acid metabolite levels and transepidermal water loss in children with atopic dermatitis. Ann Allergy Asthma Immunol. 2008 Jan;100(1):66-73.

36. Andreassi M, Forleo P, Di Lorio A, Masci S, Abate G, Amerio P. Efficacy of gamma-linolenic acid in the treatment of patients with atopic dermatitis. J Int Med Res. 
1997 Sep-Oct;25(5):266-74.

37. van Gool CJ, Thijs C, Henquet CJ, et al. Gamma-linolenic acid supplementation for prophylaxis of atopic dermatitis--a randomized controlled trial in infants at high familial risk. Am J Clin Nutr. 2003 Apr;77(4):943-51.

38. Morse NL, Clough PM. A meta-analysis of randomized, placebo-controlled clinical trials of Efamol evening primrose oil in atopic eczema. Where do we go from here in light of more recent discoveries? Curr Pharm Biotechnol. 2006 Dec;7(6):503-24.

39. Simon D, Eng PA, Borelli S, et al. Gamma-linolenic acid levels correlate with clinical efficacy of evening primrose oil in patients with atopic dermatitis. Adv Ther. 2014 Feb; 31(2):180-8.

40. Foolad N, Brezinski EA, Chase EP, Armstrong AW. Effect of nutrient supplementation on atopic dermatitis in children: a systematic review of probiotics, prebiotics, formula, and fatty acids. JAMA Dermatol. 2013 Mar;149(3): 350-5.

41. Amagai Y, Oida K, Matsuda A, et al. Dihomo- $\gamma$-linolenic acid prevents the development of atopic dermatitis through prostaglandin D1 production in NC/Tnd mice. J Dermatol Sci. 2015 Jul;79(1):30-7.

42. Yoshida S, Yasutomo $\mathrm{K}$, Watanabe $\mathrm{T}$. Treatment with DHA/EPA ameliorates atopic dermatitis-like skin disease by blocking LTB4 production. J Med Invest. 2016;63(3-4): 187-91.

43. Fujii M, Ohyanagi C, Kawaguchi N, et al. Eicosapentaenoic acid ethyl ester ameliorates atopic dermatitis-like symptoms in special diet-fed hairless mice, partly by restoring covalently bound ceramides in the stratum corneum. Exp Dermatol. 2018 Aug;27(8):837-40.

44. Kragballe K, Voorhees JJ, Goetzl EJ. Inhibition by leukotriene B5 of leukotriene B4-induced activation of human keratinocytes and neutrophils. J Invest Dermatol. 1987 May;88(5):555-8.

45. Kim TH, Kim GD, Jin YH, Park YS, Park CS. Omega-3 fatty acid-derived mediator, Resolvin E1, ameliorates 2,4dinitrofluorobenzene-induced atopic dermatitis in $\mathrm{NC} /$ Nga mice. Int Immunopharmacol. 2012 Dec;14(4):384-91.

46. Furuhjelm C, Warstedt K, Fagerås M, et al. Allergic disease in infants up to 2 years of age in relation to plasma omega-3 fatty acids and maternal fish oil supplementation in pregnancy and lactation. Pediatr Allergy Immunol. 2011 Aug;22(5):505-14.

47. Alesa DI, Alshamrani HM, Alzahrani YA, Alamssi DN, Alzahrani NS, Almohammadi ME. The role of gut microbiome in the pathogenesis of psoriasis and the therapeutic effects of probiotics. J Family Med Prim Care. 2019 Nov;8(11):3496-503.

48. Lise M, Mayer I, Silveira M. Use of probiotics in atopic dermatitis. Rev Assoc Med Bras (1992). 2018 Nov;64(11): 997-1001.

49. Rusu E, Enache G, Cursaru R, et al. Prebiotics and probiotics in atopic dermatitis. Exp Ther Med. 2019 Aug;18(2): 926-31.

50. McLoughlin RM, Mills KH. Influence of gastrointestinal commensal bacteria on the immune responses that mediate allergy and asthma. J Allergy Clin Immunol. 2011 May;127(5):1097-107; quiz 108-9.

51. Rather IA, Bajpai VK, Kumar S, Lim J, Paek WK, Park YH. Probiotics and atopic dermatitis: an overview. Front Microbiol. 2016;7:507.

52. Arpaia N, Campbell C, Fan X, et al. Metabolites produced by commensal bacteria promote peripheral regulatory $\mathrm{T}$ cell generation. Nature. 2013 Dec 19;504(7480):451-5.

53. Panduru M, Panduru NM, Sălăvăstru CM, Tiplica GS. Probiotics and primary prevention of atopic dermatitis: a meta-analysis of randomized controlled studies. J Eur Acad Dermatol Venereol. 2015 Feb;29(2):232-42.

54. Jiang W, Ni B, Liu Z, et al. The role of probiotics in the prevention and treatment of atopic dermatitis in children: An updated systematic review and meta-analysis of randomized controlled trials. Paediatr Drugs. 2020 Oct;22(5): 535-49.

55. Prasad AS. Clinical, immunological, anti-inflammatory and antioxidant roles of zinc. Exp Gerontol. 2008 May;43 (5):370-7.

56. Guttek K, Wagenbrett L, Reinhold A, Grüngreiff K, Reinhold D. Zinc aspartate suppresses proliferation and Th1/ Th2/Th17 cytokine production of pre-activated human $\mathrm{T}$ cells in vitro. J Trace Elem Med Biol. 2018 Sep;49:86-90.

57. Maywald M, Rink L. Zinc supplementation induces CD4 $(+)$ CD25(+)Foxp3(+) antigen-specific regulatory $\mathrm{T}$ cells and suppresses IFN- $\gamma$ production by upregulation of Foxp 3 and KLF-10 and downregulation of IRF-1. Eur J Nutr. 2017 Aug;56(5):1859-69.

58. Ehlayel MS, Bener A. Risk factors of zinc deficiency in children with atopic dermatitis. Eur Ann Allergy Clin Immunol. 2020 Jan;52(1):18-22.

59. Karabacak E, Aydin E, Kutlu A, et al. Erythrocyte zinc level in patients with atopic dermatitis and its relation to SCORAD index. Postepy Dermatol Alergol. 2016 Oct;33 (5):349-52.

60. Kim JE, Yoo SR, Jeong MG, Ko JY, Ro YS. Hair zinc levels and the efficacy of oral zinc supplementation in patients with atopic dermatitis. Acta Derm Venereol. 2014 Sep;94 (5):558-62.

(Received, December 25, 2020)

(Accepted, February 3, 2021)

(J-STAGE Advance Publication, March 9, 2021)

Journal of Nippon Medical School has adopted the Creative Commons Attribution-NonCommercial-NoDerivatives 4.0 International License (https://creativecommons.org/licenses/by-nc-nd/4.0/) for this article. The Medical Association of Nippon Medical School remains the copyright holder of all articles. Anyone may download, reuse, copy, reprint, or distribute articles for non-profit purposes under this license, on condition that the authors of the articles are properly credited. 